\title{
ON ASYMPTOTICALLY LACUNARY STATISTICAL EQUIVALENT SEQUENCES IN PROBALISTIC NORMED SPACE
}

\author{
Ayhan Esi \\ Department of Mathematics, Science and Art Faculty, Adiyaman University, 02040, Adiyaman, Turkey
}

Received 2012-07-02, Revised 2012-10-14; Accepted 2013-05-15

\begin{abstract}
In this study we study the new concept of asymptotically lacunary statistical convergent sequences in probabilistic normed spaces and prove some basic properties.

Keywords: Statistical Convergence, Lacunary Sequence, Asymptotic Equivalence, T Norm, Probabilictic Normed Space, Basic Properties
\end{abstract}

\section{INTRODUCTION}

Marouf (1993) presented definitions for asymptotically equivalent sequences and asymptotic regular matrices. Patterson (2003), extended those concepts by presenting an asymptotically statistical equivalent analog of these definitions and natural regularity conditions for non-negative sum ability matrices. In Patterson and Savas (2006) extended the definitions presented in (Patterson, 2003) to lacunary sequences. This study extends the definitions presented in (Patterson and Savas, 2006) to lacunary sequences in probabilistic normed space.

An interesting and important generalization of the notion of metric space was introduced by Menger (1942) under the name of statistical metric, which is now called probabilistic metric space. The notion of a probabilistic metric space corresponds to the situations when we do not know exactly the distance between two points; we know only probabilities of possible values of this distance. The theory of probabilistic metric space was developed by numerous authors, as it can be realized upon consulting the list of references in (Constantin and Istratescu, 1989), as well as those in (Schweizer and Sklar, 1960; 1983). Probabilistic normed spaces (briefly, PN-spaces) are linear spaces in which the norm of each vector is an appropriate probability distribution function rather than a number. Such spaces were introduced by Serstnev (1963). Alsina et al. (1993), gave a new definition of PN-spaces which includes Serstnev's a special case and leads naturally to the identification of the principle class of PN-spaces, the Menger spaces. Important families of probabilistic metric spaces are probabilistic normed spaces. The theory of probabilistic normed spaces is important as a generalization of deterministic results of linear normed space.

It seems therefore reasonable to think if the concept of statistical convergence can be extended to probabilistic normed spaces and in that case enquire how the basic properties are affected. But basic properties do not hold on probabilistic normed spaces. The problem is that the triangle functions in such spaces.

In this study we study the concept of asymptotically lacunary statistical convergent sequences on probabilistic normed spaces. Since the study of convergence in PNspaces is fundamental to probabilistic functional analysis, we feel that the concept of symptotically lacunary statistical convergent sequences in a PN-space would provide a more general framework for the subject.

\subsection{Prelimiaries}

Now we recall some notations and definitions used in study.

\section{Definition 2.1}

Marouf (1993) two non-negative sequences $\mathrm{x}=\left(\mathrm{x}_{\mathrm{k}}\right)$ and $\mathrm{y}=\left(\mathrm{y}_{\mathrm{k}}\right)$ are said to be asymptotically equivalent if:

$$
\lim _{\mathrm{k}} \frac{\mathrm{xk}}{\mathrm{yk}}=1,(\text { denoted by } \mathrm{x} \sim \mathrm{y})
$$




\section{Definition 2.2}

Freedmann et al. (1978) let $\mathrm{K}$ be a subset of $\mathbb{N}$; the set of natural numbers. Then the asymptotic density of $\mathrm{K}$, denoted by $\delta(\mathrm{K})$, is defined as:

$$
\delta(\mathrm{k}) \lim _{\mathrm{n}} \frac{1}{\mathrm{n}}|\{\mathrm{k} \leq \mathrm{n}: \mathrm{k} \in \mathrm{K}\}|
$$

where the vertical bars denote the cardinality of the enclosed set.

\section{Definition 2.3}

Fridy (1988) a number sequence $\mathrm{x}=\left(\mathrm{x}_{\mathrm{k}}\right)$ is said to be statistically convergent to the number 1 if for each $\varepsilon>0$, the set $\mathrm{K}(\varepsilon)=\left\{\mathrm{k} \leq \mathrm{n}:\left|\mathrm{x}_{\mathrm{k}}-\mathrm{l}\right| \geq \varepsilon\right\}$ has asymptotic density zero, i.e.:

$$
\lim _{n} \frac{1}{n}\left\{k \leq n:\left|x_{k}-1\right| \geq \varepsilon\right\} \mid=0
$$

In this case we write st- $\lim x=1$.

The next definition is natural combination of definitions 2.1 and 2.2.

\section{Definition 2.4}

Patterson (2003) two non-negative sequences $x=\left(x_{k}\right)$ and $\mathrm{y}=\left(\mathrm{y}_{\mathrm{k}}\right)$ are said to be asymptotically statistical equivalent of multiple 1 provided that for every $\varepsilon>0$ :

$$
\lim _{n} \frac{1}{n}\left|\left\{k \leq n:\left|\frac{x_{k}}{y_{k}}-1\right| \geq \varepsilon\right\}\right|=0,\left(\text { denoted by } x{\underset{\sim}{1}}^{1} y\right)
$$

and simply asymptotically statistical equivalent if $1=$ 1. Let $\mathrm{S}$ denote all sequences $\mathrm{x}=\left(\mathrm{x}_{\mathrm{k}}\right)$ and $\mathrm{y}=\left(\mathrm{y}_{\mathrm{k}}\right)$ such that $x \operatorname{\sim }_{\sim}^{1} \mathrm{y}$.

By a lacunary sequence $\theta=\left(k_{r}\right) r=0,1,2, .$. , where $k_{o}$ $=0$; we shall mean an increasing sequence of nonnegative integers with $\mathrm{h}_{\mathrm{r}}=\mathrm{k}_{\mathrm{r}}-\mathrm{k}_{\mathrm{r}}-1 \rightarrow \infty$ as $\mathrm{r} \rightarrow \infty$. The intervals determined by $\theta$ will be denoted by $\mathrm{I}_{\mathrm{r}}=\left(\mathrm{k}_{\mathrm{r}-1}\right.$, $\mathrm{k}_{\mathrm{r}}$ ] and the ratio $\frac{\mathrm{k}_{\mathrm{r}}}{\mathrm{k}_{\mathrm{r}-1}}$ will be denoted by $\mathrm{q}_{\mathrm{r}}$.

\section{Definition 2.5}

Patterson and Savas (2006) let $\theta=\left(\mathrm{k}_{\mathrm{r}}\right)$ be a lacunary sequence, the two non-negative sequences $\mathrm{x}=\left(\mathrm{x}_{\mathrm{k}}\right)$ and $\mathrm{y}$ $=\left(\mathrm{y}_{\mathrm{k}}\right)$ are said to be asymptotically lacunary statistical equivalent of multiple 1 provided that $\varepsilon>0$ :

$$
\lim _{\mathrm{r}} \frac{1}{\mathrm{~h}_{\mathrm{r}}}\left|\left\{\mathrm{k} \in \mathrm{I}_{\mathrm{r}}:\left|\frac{\mathrm{xk}}{\mathrm{yk}}-1\right| \geq \varepsilon\right\}\right|=0,\left(\text { denoted by } \mathrm{x} \underset{\sim}{\left.S_{\theta}^{1} \mathrm{y}\right)}\right.
$$

and simply asymptotically lacunary statistical equivalent if $1=1$. Let $S_{\theta}$ denote all sequences $x=\left(x_{k}\right)$ and $y=\left(y_{k}\right)$ such that $\mathrm{x} \underset{\sim}{S_{\theta}^{1} \mathrm{y}}$.

For the following concepts, we refer to Menger (1942) and Schweizer and Sklar (1960; 1983).

\section{Definition 2.6}

Menger (1942) a function $f: \mathbb{R} \rightarrow \mathbb{R}_{\mathrm{o}}^{+}$is called a distribution function if it is non-decreasing and left continuous with $\inf _{t \in \mathbb{R}} f(t)=0$ and $\sup _{t \in \mathbb{R}} f(t)=1$. We will denote the set of all distribution functions by $\mathrm{D}$.

\section{Definition 2.7}

Menger (1942) a triangular norm, briefly t-norm, is a binary operation on $[0,1]$ which is continuous, commutative, associative, non-decreasing and has 1 as.

Identity element, that is, it is the continuous mapping $*:[0,1] \times[0,1] \rightarrow[0,1]$ such that for all a, b, $c \in[0,1]:$

- $a>1=a$

- $a>b=b>a$

- $\quad c>d \geq a>b$ if $c \geq a$ and $d \geq b$

- $\quad(a>b)>c=a>(b>c)$

\section{Example 2.1}

The $>$ operations $\mathrm{a}>\mathrm{b}=\max \{\mathrm{a}+\mathrm{b}-1,0\}, \mathrm{a}>\mathrm{b}=$ a.b and $a>b=\min \{a, b\}$ on $[0,1]$ are t-norms.

\section{Definition 2.8}

Schweizer and Sklar $(1960 ; 1983)$ a triple $(\mathrm{X}, \mathrm{N},>)$ is called a probabilistic normed space or shortly $\mathrm{PN}$-space if $\mathrm{X}$ is a real vector space, $\mathrm{N}$ is a mapping from $\mathrm{X}$ into $\mathrm{D}$ (for $x \in X$, the distribution function $N(x)$ is denoted by $N_{x}$ and $N_{x}(t)$ is the value of $N_{x}$ at $t \in \mathbb{R}$ ) and $>$ is a t-norm satisfying the following conditions:

- $\quad(\mathrm{PN}-1) \mathrm{N}_{\mathrm{x}}(0)=0$

- $(\mathrm{PN}-2) \mathrm{N}_{\mathrm{x}}(\mathrm{t})=1$ for all $\mathrm{t}>0$ if and only if $\mathrm{x}=0$

- $\quad(P N-3) N_{a x}(t)=N_{x}\left(\frac{t}{|\alpha|}\right)$ for all $\alpha \in R /\{0\}$

- $\quad(P N-4) N_{x+y}(s+t) \geq N_{x}(s)>N_{y}$ (t) for all $x, y \in X$ and $\mathrm{s}, \mathrm{t} \in \mathbb{R}_{\mathrm{o}}^{+}$

\section{Example 2.2}

Suppose that $(X,\|\|$.$) is a normed space \mu \in D$ with $\mu(0)=0$ and $\mu \neq h$, where: 


$$
h(t)=\left\{\begin{array}{l}
0, t \leq 0 \\
1, t>0
\end{array}\right.
$$

Define:

$$
\mathrm{N}_{\mathrm{x}}(\mathrm{t})=\left\{\begin{array}{cc}
\mathrm{h}(\mathrm{x}), & \mathrm{x}=0 \\
\mu\left(\frac{\mathrm{t}}{\|\mathrm{x}\|}\right), & \mathrm{x} \neq 0
\end{array}\right.
$$

where, $x \in X, t \in \mathbb{R}$. Then $(X, N,>)$ is a PN-space. For example if we define the functions $\mu$ and $\nu$ on $\mathbb{R}$ by:

$$
\mu(x)=\left\{\begin{array}{c}
0 x, \leq 0 \\
\frac{x}{1+x}, x>0
\end{array}, v(x)\left\{\begin{array}{c}
0, x \leq 0 \\
e \frac{-1}{x}, x>0
\end{array}\right.\right.
$$

Then we obtain the following well-known > norms:

$$
N_{x}(x)=\left\{\begin{array}{c}
h(t), x=0 \\
\frac{t}{t+\|x\|}, x \neq 0
\end{array}, \quad M_{x}(t)=\left\{\begin{array}{c}
h(t), x=0 \\
e\left(\frac{-\|\infty\|}{t}\right), x \neq 0
\end{array}\right.\right.
$$

We recall the concepts of convergence and Cauchy sequences in a probabilistic normed space.

\section{Definition 2.9}

Asadollah and Nourouzi (2008) let (X, N, >) is a PNspace. Then a sequence $\mathrm{X}=\left(\mathrm{x}_{\mathrm{k}}\right)$ is said to be convergent to $l \in \mathrm{X}$ with respect to the probabilistic norm $\mathrm{N}$ if, for every $\varepsilon>0$ and $\theta \in(0,1)$, there exists a positive integer $\mathrm{k}_{\mathrm{o}}$ such that $\mathrm{N}_{\mathrm{xk}-1}(\varepsilon)>1-\theta$ whenever $\mathrm{k} \geq \mathrm{k}_{\mathrm{o}}$. It is denoted by $\mathrm{N}-\lim \mathrm{x}=\mathrm{L}$ or $\mathrm{x}_{\mathrm{k}} \stackrel{\mathrm{N}}{\longrightarrow} \mathrm{L}$ as $\mathrm{k} \rightarrow \infty$.

\section{Definition 2.10}

Asadollah and Nourouzi (2008) let (X, N, >) is a PNspace. Then a sequence $\mathrm{x}=\left(\mathrm{x}_{\mathrm{k}}\right)$ is called a Cauchy sequence with respect to the probabilistic norm $\mathrm{N}$ if, for every $\varepsilon>0$ and $\theta \in(0,1)$, there exists a positive integer $k_{o}$ such that $\mathrm{N}_{\mathrm{xk}-\mathrm{xl}}(\varepsilon)>1-\theta$ for all $\mathrm{k}, 1 \geq \mathrm{k}_{\mathrm{o}}$.

\section{Definition 2.11}

Asadollah and Nourouzi (2008) let (X, N, >) is a PNspace. Then a sequence $\mathrm{X}=\left(\mathrm{x}_{\mathrm{k}}\right)$ is said to be bounded in $X$, if there is a $r \in \mathbb{R}$ such that $N_{x k}(r)>1-\theta$, where $\theta \in$ $(0,1)$. We denote by $1_{\infty}^{\mathrm{N}}$ the space of all bounded sequences in $\mathrm{PN}$ space.

\subsection{Asymptotically Lacunary Convergence on PN-Spaces}

The idea of statistical convergence was first introduced by Steinhaus (1951) and then studied by various authors, e.g., (Salat, 1980; Fridy, 1988; Connor, 1988; Esi, 1996) and many others and in normed space by Kolk (1988). Recently Karakus (2007) has studied the concept of statistical convergence in probabilistic normed spaces.

\section{Definition 3.1}

Karakus (2007) let (X, N, >) is a PN-space. Then a sequence $\mathrm{X}=\left(\mathrm{x}_{\mathrm{k}}\right)$ is said to be statistically convergent to $1 \in \mathrm{X}$ with respect to the probabilistic norm $\mathrm{N}$ provided that for every $\varepsilon>0$ and $\gamma \in(0,1)$ :

$$
\delta\left(\left\{\mathrm{k} \in \mathbb{N}: \mathrm{N}_{\mathrm{xk}-1}(\varepsilon) \leq 1-\gamma\right\}\right)=0
$$

Or equivalently:

$$
\lim _{\mathrm{n}} \frac{1}{\mathrm{n}}\left|\left\{\mathrm{k} \leq \mathrm{n}: \mathrm{N}_{\mathrm{xk}-1}(\varepsilon) \leq 1-\gamma\right\}\right|=0
$$

In this case we write $\mathrm{st}_{\mathrm{N}}-\lim \mathrm{x}=1$. We are now ready to obtain our main results.

\section{Definition 3.2}

Let $(\mathrm{X}, \mathrm{N},>)$ is a PN-space and $\theta=\left(\mathrm{k}_{\mathrm{r}}\right)$ be a lacunary sequence. The two non-negative sequences $\mathrm{x}=\left(\mathrm{x}_{\mathrm{k}}\right)$ and $\mathrm{y}$ $=\left(\mathrm{y}_{\mathrm{k}}\right)$ are said to be asymptotically lacunary statistical equivalent of multiple 1 in $\mathrm{PN}$-space $\mathrm{X}$ if for every $\varepsilon>0$ and $\gamma \in(0,1)$ Equation 1:

$\delta_{\theta}\left(\left\{\mathrm{k} \in \mathrm{I}_{\mathrm{r}}: \mathrm{N}_{\frac{\mathrm{ok}}{\mathrm{yk}}-1}(\varepsilon) \leq 1-\gamma\right\}\right)=0$

Or equivalently:

$$
\lim _{\mathrm{r}} \frac{1}{\mathrm{~h}_{\mathrm{r}}}\left|\left\{\mathrm{k} \in \mathrm{I}_{\mathrm{r}}: \mathrm{N}_{\frac{\infty \mathrm{k}}{\mathrm{yk}}-1}(\varepsilon) \leq 1-\gamma\right\}\right|=0
$$

In this case we write $\mathrm{xS}_{\theta}^{1}(\underset{\sim}{\mathrm{PN}}) \mathrm{y}$ and simply asymptotically lacunary statistical equivalent if $1=1$. Furthermore, let $S_{\theta}^{1}(\underset{\sim}{P N})$ denote the set of all sequences $\mathrm{x}$ $=\left(\mathrm{x}_{\mathrm{k}}\right)$ and $\mathrm{y}=\left(\mathrm{y}_{\mathrm{k}}\right)$ such that $\mathrm{x} \mathrm{S}_{\theta}^{1}(\underset{\sim}{\mathrm{PN}}) \mathrm{y}$.

By using (3.1) and well-known density properties, we easily get the following lemma.

\section{Lemma 3.1}

Let $(\mathrm{X}, \mathrm{N},>)$ is a PN-space. Then, for every $\varepsilon>0$ and $2(0,1)$, the following statements are equivalent: 
- $\lim _{\mathrm{r}} \frac{1}{\mathrm{~h}_{\mathrm{r}}}\left|\left\{\mathrm{k} \in \mathrm{I}_{\mathrm{r}}: \mathrm{N}_{\frac{\mathrm{ok}}{\mathrm{yk}}-1}(\varepsilon) \leq 1-\gamma\right\}\right|=0$

- $\delta_{\theta}\left(\left\{\mathrm{k} \in \mathrm{I}_{\mathrm{r}}: \mathrm{N}_{\frac{\infty \mathrm{k}}{\mathrm{yk}}-1}(\varepsilon) \leq 1-\gamma\right\}\right)=0$

- $\delta_{\theta}\left(\left\{\mathrm{k} \in \mathrm{I}_{\mathrm{r}}: \mathrm{N}_{\frac{\mathrm{ck}}{\mathrm{yk}}-1}(\varepsilon)>1-\gamma\right\}\right)=1$

- $\quad \lim _{\mathrm{r}} \frac{1}{\mathrm{~h}_{\mathrm{r}}}\left\{\left\{\mathrm{k} \in \mathrm{I}_{\mathrm{r}}: \mathrm{N}_{\frac{\infty \mathrm{k}}{\mathrm{yk}}-1}(\varepsilon)>1-\gamma\right\} \mid=1\right.$

\section{Theorem 3.2}

Let $(\mathrm{X}, \mathrm{N},>)$ is a PN-space. If two sequences $\mathrm{x}=\left(\mathrm{x}_{\mathrm{k}}\right)$ and $\mathrm{y}=\left(\mathrm{y}_{\mathrm{k}}\right)$ are asymptotically lacunary statistical equivalent of multiple 1 with respect to the probabilistic norm $\mathrm{N}$, then $\mathrm{l}$ is unique.

\section{Proof}

Assume that $x S_{\theta}^{1_{1}}(\mathrm{PN})$ y and $x S_{\theta}^{1_{2}}(P N) y,\left(1_{1} 6 \neq 1_{2}\right)$. For a given $\lambda>0$ choose $\gamma \in(0,1)$ such that $(1-\gamma)>(1-\gamma)>$ $1-\lambda$. Then, for any $\varepsilon>0$, define the following sets:

$$
\mathrm{K}_{1}=\left\{\mathrm{k} \in \mathrm{I}_{\mathrm{r}}: \mathrm{N}_{\frac{\infty \mathrm{k}}{\mathrm{yk}} \mathrm{k}_{1}}(\varepsilon) \leq 1-\gamma\right\}
$$

And:

$$
\mathrm{K}_{1}=\left\{\mathrm{k} \in \mathrm{I}_{\mathrm{r}}: \mathrm{N}_{\frac{\mathrm{ck}}{\mathrm{yk}} \mathrm{I}_{2}}(\varepsilon) \leq 1-\gamma\right\}
$$

Then, clearly:

$$
\lim _{\mathrm{r}} \frac{\left|\mathrm{K}_{1} \cap \mathrm{K}_{2}\right|}{\mathrm{h}_{\mathrm{r}}}=1
$$

So $K_{1} \cap K_{2}$ is non-empty set. Since $x S_{\theta}^{1_{1}}(P N) y, \quad \delta_{\theta}$ $\left(\mathrm{K}_{1}\right)=0$ and $\mathrm{x} \mathrm{S}_{\theta}^{\mathrm{l}_{2}}(\mathrm{PN}) \mathrm{y}, \delta_{\theta}\left(\mathrm{K}_{2}\right)=0$ for all $\varepsilon>0$. Now let $\mathrm{K}=\mathrm{K}_{1} \cap \mathrm{K}_{2}$. Then we observe that $\delta_{\theta}(\mathrm{K})=0$ which implies $\delta_{\theta}(\mathbb{N}-\mathrm{K})=1$. If $\mathrm{k} \in \mathbb{N}-\mathrm{K}$; then we have:

$$
\begin{aligned}
& \mathrm{Nl}_{1-\mathrm{I}_{2}}(\varepsilon)=\mathrm{N}_{\frac{\mathrm{ck}}{\mathrm{yk}}-1_{1}-1_{2}}(\varepsilon) \geq \mathrm{N}_{\frac{\mathrm{ck}}{\mathrm{yk}}-1_{1}} \\
& \left(\frac{\varepsilon}{2}\right)>\mathrm{N}_{\frac{\rho \mathrm{kk}}{\mathrm{yk}}-\mathrm{I}_{2}}\left(\frac{\varepsilon}{2}\right)>(1-\gamma)>(1-\gamma) \geq 1-\lambda
\end{aligned}
$$

Since $\lambda>0$ was arbitrary, we get $\mathrm{N}_{1_{1}-\mathrm{I}_{2}}(\varepsilon)=1$ for all $\varepsilon>0$, which gives $1_{1}=l_{2}$. This completes the proof.

\section{Theorem 3.3}

Let $(\mathrm{X}, \mathrm{N},>)$ is a PN-space. For any lacunary sequence $\theta=\left(k_{\mathrm{r}}\right), \mathrm{S}_{\theta}(\mathrm{PN}) \subset \mathrm{S}$ if $\lim \sup _{\mathrm{r}} \mathrm{q}_{\mathrm{r}}<\infty$.

\section{Proof}

If $\lim \sup _{\mathrm{r}} \mathrm{q}_{\mathrm{r}}<\infty$ then there exists a B $>0$ such that $\mathrm{q}_{\mathrm{r}}$ $<\mathrm{B}$ for all $\mathrm{r} \geq 1$. Let $\mathrm{x}_{\theta}^{\mathrm{I}_{1}}\left(\mathrm{P}_{\sim}^{\mathrm{PN}}\right) \mathrm{y}$ and $\varepsilon>0$. We are going to prove $\mathrm{x} \mathbf{S}^{1} \mathrm{y}$. Set:

$$
\mathrm{K}_{\mathrm{r}}=\left|\left(\mathrm{k} \in \mathrm{I}_{\mathrm{r}}: \mathrm{N}_{\frac{\mathrm{ck}}{\mathrm{yk}}-1}(\varepsilon)>1-\gamma\right)\right|
$$

Then, by definition, for given $\varepsilon>0$, there exists $r_{o} \in \mathbb{N}$ such that:

$$
\frac{\mathrm{K}_{\mathrm{r}}}{\mathrm{h}_{\mathrm{r}}}<\frac{\varepsilon}{2 \mathrm{~B}} \text { for all } \mathrm{r} \geq \mathrm{r}_{\mathrm{o}}
$$

Let $\mathrm{M}=\max \left\{\mathrm{K}_{\mathrm{r}}: 1 \leq \mathrm{r} \leq \mathrm{r}_{\mathrm{o}}\right\}$ and let $\mathrm{n}$ be any integer with $\mathrm{k}_{\mathrm{r}-1}<\mathrm{n} \leq \mathrm{k}_{\mathrm{r}}$.

Then:

$$
\begin{aligned}
& \frac{1}{\mathrm{n}}\left|\left\{\mathrm{k} \leq \mathrm{n}: \mathrm{N}_{\frac{\infty \mathrm{k}}{\mathrm{yk}}-1}(\varepsilon)>1-\gamma\right\}\right| \\
& \leq \frac{1}{\mathrm{k}_{\mathrm{r}-1}}\left|\left\{\mathrm{k} \leq \mathrm{k}_{\mathrm{r}}: \mathrm{N}_{\frac{\infty \mathrm{k}}{\mathrm{yk}}-1}(\varepsilon)>1-\gamma\right\}\right| \\
& =\frac{1}{\mathrm{k}_{\mathrm{r}-1}}\left\{\mathrm{~K}_{1}+\mathrm{K}_{2}+\ldots+\mathrm{K}_{\mathrm{ro}}+\ldots+\mathrm{K}_{\mathrm{r}}\right\} \\
& \leq \frac{\mathrm{M}}{\mathrm{k}_{\mathrm{r}-1}} \mathrm{r}_{\mathrm{o}}+\frac{\varepsilon}{2 \mathrm{~B}} \mathrm{q}_{\mathrm{r}} \leq \frac{\mathrm{M}}{\mathrm{k}_{\mathrm{r}-1}} \mathrm{r}_{\mathrm{o}}+\frac{\varepsilon}{2}
\end{aligned}
$$

and the result follows immediately.

\section{Theorem 3.4}

Let $(\mathrm{X}, \mathrm{N},>)$ is a $\mathrm{PN}$-space. For any lacunary sequence $\theta=\left(k_{r}\right), S \subset S_{\theta}(P N)$ if $\lim _{\inf _{r}} q_{r}>1$.

\section{Proof}

If $\lim \inf _{\mathrm{r}} \mathrm{q}_{\mathrm{r}}>1$, then there exists a $\beta>0$ such that $\mathrm{q}_{\mathrm{r}}>1$ $+\beta$ for sufficiently large $r$, which implies:

$$
\frac{\mathrm{h}_{\mathrm{r}}}{\mathrm{k}_{\mathrm{r}}} \geq \frac{\beta}{1+\beta}
$$


Let $\mathrm{x}_{\sim}^{\mathrm{S}} \mathrm{y}$, then for every $\varepsilon>0$ and for sufficiently large $r$, we have:

$$
\begin{aligned}
& \frac{1}{\mathrm{k}_{\mathrm{r}}}\left|\left\{\mathrm{k} \leq \mathrm{k}_{\mathrm{r}}: \mathrm{N}_{\frac{\infty \mathrm{k}}{\mathrm{yk}}-1}(\varepsilon)>1-\gamma\right\}\right| \\
& \geq \frac{1}{\mathrm{k}_{\mathrm{r}}}\left|\left\{\mathrm{k} \in \mathrm{I}_{\mathrm{r}}: \mathrm{N}_{\frac{\infty \mathrm{k}}{\mathrm{yk}}-1}(\varepsilon)>1-\gamma\right\}\right| \\
& \geq \frac{\beta}{1+\beta} \frac{1}{\mathrm{~h}_{\mathrm{r}}}\left|\left\{\mathrm{k} \in \mathrm{I}_{\mathrm{r}}: \frac{\mathrm{N}_{\frac{\infty \mathrm{k}}{\mathrm{yk}}-1}}{}(\varepsilon)>1-\gamma\right\}\right|
\end{aligned}
$$

Therefore $\mathrm{x} \mathrm{S}_{\theta_{\sim}^{1}}^{1}(\mathrm{PN}) \mathrm{y}$. This completes the proof.

\section{Corollary 3.5}

Let $(\mathrm{X}, \mathrm{N},>)$ is a PN-space. For any lacunary sequence $\theta=\left(\mathrm{k}_{\mathrm{r}}\right)$ with $1<\lim \inf _{\mathrm{r}} \mathrm{q}_{\mathrm{r}} \leq \lim \sup _{\mathrm{r}} \mathrm{q}_{\mathrm{r}}<\infty$, then $\mathrm{S}=\mathrm{S}_{\theta}(\mathrm{PN})$.

\section{Proof}

The result clearly follows from Theorem 3.3 and 3.4.

\section{CONCLUSION}

The idea of probabilistic norm is very useful to deal with the convergence problems of sequences of real numbers. The main purpose of this study is to more generalize the results on statistical convergence proved by Karakus (2007). We have introduced a wider class of asymptotically lacunary statistically convergent sequences in a PN-space to deal with the sequences which are not covered in (Karakus, 2007).

\section{REFERENCES}

Alsina, C., B. Schweizer and A. Sklar, 1993. On the definition of a probabilistic normed space. Aequationes Math., 46: 91-98. DOI: 10.1007/BF01834000

Asadollah, A. and K. Nourouzi, 2008. Convex sets in probabilistic normed spaces. Chaos, Solitons Fractals, 36: 322-328. DOI: 10.1016/j.chaos.2006.06.051
Connor, J.S., 1988. The statistical and strong p-Cesaro convergence of sequences. Analysis, 8: 47-63.

Constantin, G. and I. Istratescu, 1989. Elements of Probabilistic Analysis with Applications. 1st Edn., Kluwer Academi, Boston, ISBN-10: 9027728380, pp: 492.

Esi, A., 1996. The A-statistical and strongly (A-p)Cesaro convergence of sequences. Pure Appli. Math. Sci., 1: 89-93.

Freedmann, A.R., J.J. Sember and M. Raphael, 1978. Some cesaro-type summability spaces. Proc. London Math. Soc., 37: 508-520. DOI: 10.1112/plms/s337.3.508

Fridy, J.A., 1988. On statistical convergence. Analysis, 5: 301-313.

Karakus, S., 2007. Statistical convergence on probalistic normed space. Math. Commun., 12: 11-23.

Kolk, E., 1988. Statistically convergent sequences in normed spaces. Tartu.

Marouf, M., 1993. Asymptotic equivalence and summability. Int. J. Math. Math. Sci., 16: 755-762. DOI: $10.1155 / \mathrm{S} 0161171293000948$

Menger, K., 1942. Statistical metrics. Proc. Nati. Acad. Sci. USA., 28: 535-537.

Patterson, R.F. and E. Savas, 2006. On asymptotically lacunary statistical equivalent sequences. J. Math., 4: $267-272$.

Patterson, R.F., 2003. On asymptotically statistical equivalent sequences. Demonstratio Math., 36: 149153.

Salat, T., 1980. On statistically convergent sequences of real numbers. Math. Slovaca, 30: 139-150.

Schweizer, B. and A. Sklar, 1960. Statistical metric spaces. Pasi. J. Math., 10: 313-334.

Schweizer, B. and A. Sklar, 1983. Probabilistic Metric Spaces. 1st Edn., North-Holland, New York, ISBN10: 0444006664, pp: 275.

Serstnev, A.N., 1963. On the notion of a random normed space. Dokl. Akad. Nauk SSSR, 149: 280-283.

Steinhaus, H., 1951. Sur la convergence ordinaire et la convergence asymptotique. Colloq. Math., 2: 73-74. 